\title{
Breaking Patricidal Anxiety: Literary Kinship and Acts of Philosophy
}

\author{
Ying, Zhou
}

\begin{abstract}
The expulsion of the poets from the city in Plato's Republic, from an original perspective, can be regarded as the turning point for the deviation between philosophy and literature in western tradition. Poetry, the most typical embodiment of literariness, is rejected. The symbolic refusal has tremendous impact on the later interaction between philosophy and literature. Though Aristotle and Philip Sidney argued for the value of poetry, literature is largely marginalized and even despised in the field of philosophy. From Jacques Derrida's view, in the text of philosophy, there exists inescapable white mythology and philosophy is white literature in nature. In this sense, the action of expelling poets contains the trace of patricide, which is a way of self-protection. Cutting off the innate connection is a way to guarantee philosophy's "self-contained" purity and safety. In the course of development of literature and philosophy, literature tends to absorb new elements from philosophy to further its own progress while philosophy is comparatively resistant to embrace literature. Invisible anxiety exists when philosophy encounters literature. This paper argues that instead of expelling poets, expelling anxiety should be the aim for the development of philosophy, for the goal that literature and philosophy target at is the same, that is human beings or Lebendigkeit in human. In philosophical tradition contains a long-lasting literary memory. The natural and internal connection between the two disciplines cannot and should not be cut off.
\end{abstract}

Keywords-literary memory, Republic, patricidal anxiety, philosophy

\section{INTRODUCTION}

Literature possesses spirituality, freedom, self-contained absolute power as well as natural justice. As Jacques Derrida stated in his Acts of Literature, "literature as historical institution with its conventions, rules, etc., but also this institution of fiction which gives in principle the power to say everything, to break free of the rules, to displace them, and thereby to institute, to invent and even to suspect the traditional difference between nature and institution, nature and conventional law, nature and history." [1] The freedom of expression is almost something innate in literature itself and needs not the further affirmation of an outer environment, be it economic, religious or political. With the absolute freedom within itself, literature tells and inquires everything in every possible way with its natural inner legitimacy. Such uncontrollable power unsettles Plato, which directly causes

Manuscript received July. 16, 2018. This work is funded by the Graduate School of Minzu University of China.

The author is now with the School of Foreign Studies, Minzu University of China. poets' expulsion from the city in Plato's Republic. "Because, if I am not mistaken, we shall have to say that about men poets and story-tellers are guilty of making the gravest misstatements when they tell us that wicked men are often happy, and the good miserable; and that injustice is profitable when undetected, but that justice is a man's own loss and another's gain - these things we shall forbid them to utter, and command them to sing and say the opposite." [2] The exceptional ardor and craziness in poets are regarded as destroyer in a well-organized Republic where justice, city-state and political system are elaborately pondered over in a serious philosophical way. Giving consideration to the overall stability and the issue of justice, Poet's speeches are controlled and smothered. Poetry is the most typical embodiment of literariness. The symbolic refusal has tremendous impact on the later interaction between philosophy and literature in western tradition.

Aristotle defensed the value of poetry in his Poetics, "It is also obvious from what we have said that it is the function of a poet to relate not things that have. happened, but things that may happen; I.e. that are possible in accordance with probability or necessity." [3] He also argued that poetry, unlike history, speaks more of universals and is thus more philosophical and more serious. From Aristotle's view, poetry is closer to the highest and the most quintessential embodiment of all forms of knowledge-philosophy. Through the defense Aristotle claimed that poetry exceeds history. Philip Sydney also argued for the natural justice of poetry. In spite of their defense of poetry, in the field of philosophy, however, the value of literature is largely marginalized and even despised. Indisputably, Plato has exerted a tremendous influence on the later development of western philosophy and to some extent, has decided the acts of philosophy. English philosopher Alfred North Whitehead even regarded the whole history of western philosophy as a series of footnotes of Plato's thinking.

On closer examination, there is more to explore behind the action of expulsion. Why poets have to be expelled from the city where philosophers are in dominance? Surely Plato's fear of the possible corrosion that poets may bring exists. But besides this, the action of expulsion would thicken if we view it from an aspect of kinship and genetic connection.

\section{LITERARY KINSHIP AND PATRICIDAL ANXIETY}

In order to reveal the literary kinship hidden behind philosophy, let me briefly introduce Harold Bloom's theorythe anxiety of influence at first. Harold Bloom has pointed it out in The Anxiety of Influence: A Theory of Poetry that younger poets are tortured and hindered by their much stronger 
fathers-those talented precursor poets. The powerful fathers have established an enormous mountain of literary cannon, which is difficult to reach, not to mention to climb over. Ambitious young poets have to struggle to walk out of the huge shadow cast by the intimidating fathers who stand firm in the kingdom of poetry. "For every poet begins (however "unconsciously") by rebelling more strongly against the consciousness of death's necessity than all other men and women do. The young citizen of poetry, or ephebe as Athens would have called him, is already the anti-natural or antithetical man, and from his start as a poet he quests for an impossible object, as his precursor quested before him." [4] By violently or sinuously breaking away from the influence of them, young poets can earn their own places. And the misreading of the prior poets is one of their special ways of patricide. In the domain of poetry, the subtle father-son relation is comparatively visible and clear. Though poets have suffered to create their own speech, the genetic connection between precursor poets and ambitious young poets is largely acknowledged. In philosophy, however, the image of the father is largely obscure and dubious, for philosophy regards itself as the ultimate father of all other branches of knowledge and there should be no such thing as its father. In other words, no legitimate room is left for such existence in the system of philosophy. So, the anxiety of influence does not seem to be one of philosophy's major concerns in an evident way. But that does not mean that philosophy is forever safe from the problem of anxiety. Though temporarily shunning the anxiety when faced with an invisible strong father, philosophy has to accept a kind of deeper anxiety which appears after the symbolic refusal of poetry. When the "threat" (literature) is near, philosophy naturally and intuitively expels it before seriously considering what does the image of the "threat" stand for. Feeling the latent risk, philosophy takes its action without much hesitation in order to defense its own inviolable domain of reason and logic. Philosophy strives to expel literary traits in serious philosophical texts in order to gain ever-lasting purity. It can be regarded as a way of natural self-protection.

Such tradition is under strong attack from philosopher Jacques Derrida. From Jacques Derrida's view, the discourse of philosophy is the discourse of literature. Jacques Derrida revealed philosophy's reliance on literature from three aspects, "Firstly, like literature, philosophy is a way of writing and is thus inevitably under the control of archetypal letters. Secondly, literature and philosophy are both confined by context and logic. Thirdly, philosophy and literature are both rhetorical discourses and are subject to the metaphorical logic of archetypal literature." [5] Such reliance may be subtle and is thus not easy to be captured. But it does exist and plays an important, and at the same time, invisible role in philosophical texts. Similarly, Jonathan Culler also pointed it out in his $O n$ Deconstruction: Theory and Criticism after Structuralism that "In theory, metaphors are contingent features of philosophical discourse; though they may play an important role in expressing and elucidating concepts, they ought in principle to be separable from the concepts and their adequacy and inadequacy, and indeed separating essential concepts from the rhetoric in which they are expressed is a fundamental philosophical task. But when one attempts to perform this task, not only is it difficult to find concepts that are not metaphorical, but the very terms in which one defines this philosophical task are themselves metaphorical." [6] From Jonathan Culler's view, even though philosophy strives to draw a clear line to guarantee its own philosophical accuracy, it is a mission impossible, for the very source of philosophical texts is under control of literary metaphor. (As for the problem of metaphor, I will leave it to the following section.) Combining Jacques Derrida and Jonathan Culler's reflection on philosophy, we will find that the action of expelling poets from the city is then intricately tinted with patricide. An ultimate embodiment of all other forms of knowledge, that is philosophy, does have a father of its own. Unaware of the existence of a stronger father and aware of a latent threat, philosophy expels literature to preserve its own independent growth. The action that philosophy takes is to cut off the innate connection to confirm philosophy's "self-contained" safety and purity. This typical action can be regarded as the turning point for the deviation between philosophy and literature in western tradition. And this action of patricide is much less noticed. Actually, in the field of philosophy, this significant symbolic patricide is utterly comparable to the famous tragic story of Oedipus.

Plato was obsessed with the world of ideas, which leads to a deviation between literature and philosophy. Traditional philosophical texts tend to refuse and expel any traits that may be literary. The overlook and resistance of literary elements have become a norm in traditional philosophical texts, which to some extent hinders the further development and new breakthrough in this field. Ever since the action of expulsion, the invisible anxiety that philosophy manifests when faced with literature can be regarded as the mode of self-protection. The action of patricide is completed and the poets have been successfully expelled from the city, yet the anxiety does not utterly disappear. Actually, the anxiety has long been there before the action of patricide and will maintain its lasting influence. Before the expulsion, anxiety serves as the invisible catalyst for the moment of patricide and after the very action, the lingering anxiety is the reminder of the haunting memory. Afraid of the resurgence of a dead father, philosophy reinforces its own authority through extensive practice of "pure philosophical language", which deepens the divergence of them.

\section{THE LINGERING QUESTIONS}

By expelling poets, Plato wanted the city-state to be safe from the spell of poetry. But the questions still linger: is there an absolute safe zone in the Republic that can be completely free of the influence of poetry and has the connection between philosophy and literature been cut off thoroughly? The answer to the questions is negative. 
The action of expulsion is patently unilateral. Literature is clearly under the continuous influence of philosophy and philosophical thoughts, which can be captured through the various ongoing literary trends in the history of western literature. For example, there exist strong connections between rationalism and literary classicism, German idealism and romantic literature, materialism and realistic literature, to name just a few. Besides, the anti-tradition and anti-rationalism modern literary trend is also closely involved with the new development in modern philosophy. Embracing the influence from philosophy, literature has absorbed the quintessence of philosophical thoughts into its own special system of creation or criticism while leaving the intricate metaphysical demonstration aside. Nurtured by philosophy, many gifted writers exhibit an impressive interdisciplinary creativity. Many examples can be given here. Euripides is praised as the philosopher on the stage. Voltaire is undoubtedly a talent in writing philosophical fiction. Albert Camus and Jean-Paul Sartre's typical existentialist fiction provides a possible space for the co-existence of literature and philosophy within texts. Compared with the hostility and hesitance that philosophy consciously or unconsciously presents, literature tends to absorb new elements from philosophy to further its own progress. The innate kinship between literature and philosophy still exists. On the one hand, literature assimilates what it needs from philosophy to fuel its own development. On the other hand, philosophy never truly gets rid of its deportee and looming father. Although the action of patricide is already completed in Plato's Republic, the problem is not solved once and for all, for literary metaphor is almost something born with philosophical texts no matter how hard they try to avoid. In this case, the fear that is once hidden behind philosophy turns into reality-the expelled father not only manages to stay alive, but also finds his way to loom in philosophical texts. The reality is largely ironic. Just as a Chinese critic Hong Yu commented in his paper, "Philosophy is what it rejects and despises for thousands of years. It is literature itself, a kind of white literature. Once we splash some color rendering potion on it, the truth it hides will be revealed." [7]

Metaphor is one of the strong and effective color rending potions that can reveal the hidden truth. Carefully considering the role that literary metaphor plays in all kind of texts, we may successfully undress the rigid military uniform of philosophy. Poetry is metaphorical. However, metaphor is, for philosophy, a latent danger that should be cautiously and prudently wiped out from serious philosophical texts. The reason behind it is easy to understand. Metaphor draws subtle similarity between two different things and thus makes its reference two-folded, which to some extent brings ambiguity. The process of employing a metaphor inevitably involves the use of imagination, which is clearly not based on careful logic induction and deduction, but a necessary transgression of the norm. In a traditional philosophical context, however, the written language of philosophy should get rid of the influence of metaphors and make itself appear to be "pure" in nature, that is to say, to be completely objective and definite. Metaphor for philosophy is like an unsettling spot in a well-cleaned window and is better to be permanently removed. But one thing that philosophy ignores is that the discourse of philosophy is inevitably entwined with metaphorical discourse from the very beginning. Jacques Derrida sharply pointed it out in his Margins of Philosophy that "In a word, the task is to consider philosophy also as a 'particular literary genre,' drawing upon the reserves of a language, cultivating, forcing, or making deviate a set of tropic resources older than philosophy itself." [8] In fact, the kinship that philosophy refuses to acknowledge exists in a much stronger and unavoidable way. Though the action of patricide is completed, the genetic connection cannot be cut off and will always serve as a company.

Inescapably influenced by the world of ideas of Plato and a metaphysical impulse, philosophy takes literary traits as something that should be intensely resisted. Because in those literary traits contain unsteady and uncontrollable factors, which are exactly what philosophy refuses to pursue. One of the important missions for philosophy is to reveal possible truth in a steady and abstract dimension of thinking. The concern that literary traits may undermine the accuracy in philosophical texts hinders the further instrumental contact between literature and philosophy. From my point of view, the new progress in philosophy truly requires a sincere contact with literature, not only because there exists natural literary memory in philosophy itself, but because it involves the motivation that philosophy needs to further its own development.

\section{ACTS OF PHILOSOPHY}

Philosophy is pushed forward and stimulated by the urge to reveal the veil of the nature. When philosophers rely on the written language to organize and systematize the philosophical thoughts, there exists a trap of pure concept. Some traditional philosophers try to purity philosophical language to clarify the answer to various questions and phenomena, which leads to two problems. Firstly, a pure philosophical language may be trapped in conceptual thoughts. Secondly, essentially speaking, there is no such thing as "pure philosophical language." The ideal pure language is the product of an ideal philosophical imagination and is thus non-existent in actual philosophical text practice. The deconstruction on philosophy that Jacques Derrida proposed is just based on the second point above. As for the first problem, an awareness of life that literature provides may release philosophy from the cage of factual truth.

A contact with literature will bring new possibility and breakthrough in an innovative way. A most typical example is Friedrich Wilhelm Nietzsche. The great philosopher with strong personal traits never purposely avoided the use of mythology and metaphor in his works. His enormous philosophical system which includes Dionysian Spirit and Phoebus Spirit contains patent literature parent. Nietzsche is a philosopher closely attached to intense literary connection. In Thus Spoke Zarathustra, Nietzsche almost adopted a poetic language and a wild state of mind to affirm his philosophical thoughts, a way that must be despised by Plato. The Nietzschean philosophical 
phenomenon is not isolated and there is a changing historical trend behind it. Viewed from a broader historical background of the development of philosophy, Irrationalism has exerted a much profound influence on the ongoing development of philosophy than we may perceive and the influence of it is largely beyond the field of philosophy. From the 19th century, Irrationalism in philosophy has found its way in philosophical system and there have emerged a series of eminent concepts such as Arthur Schopenhauer's philosophical world as will and representation, Søron Aabye Kierkegaard's freedom of will as well as Nietzsche's will to power. Besides, philosophical trend Lebensphilosophie firstly became popular in the beginning of the 20th century and it had connection with the concern of human existence itself. One common feature of the philosophical thoughts above is that they value much more on human life experience and existence instead of factual life and factual truth. The noted philosopher Martin Heidegger also agreed that the primary concern of philosophy should be human themselves. The very divergence of Martin Heidegger and Edmund Gustav Albrecht Husserl partly results from this. Refusing the old philosophy and the absolute thingness in it, Heidegger once pointed out that "methodological crossroads that will be decisive for the life or death of philosophy in general" [9] Heidegger's words stood for a turn in philosophy, from Dingheit to Lebendigkeit. The turn, according to Heidegger, is crucial, for it has a direct influence on the life of philosophy. Heidegger's value on human experience also explains why he deeply resonated with Friedrich Hölderlin's verses and made "Deserving, yet poetically, we dwell on this earth." [10] such a famous statement. Heidegger's ontology had an obvious and direct influence on his student Hans-Georg Gadamer, whose Hermeneutics starts from ontology. Hans-Georg Gadamer argued in his important work Truth and Method that "The understanding and the interpretation of texts is not merely a concern of science, but is obviously part of the total human experience of the world. The hermeneutic phenomenon is basically not a problem of method at all. It is not concerned with a method of understanding by means of which texts are subjected to scientific investigation like all other objects of experience" [11] Hans-Georg Gadamer is similar to his teacher Heidegger in this regard.

The danger faced by philosophy that Heidegger once mentioned will loom if philosophy still remains in a pure theoretical stage where metaphysical argument takes domination. In that case, philosophy largely overlooks the importance of human life. It is human experience instead of factual life that should be the study object of philosophy. The end of literature is in human beings. In this sense, literature provides another form of truth. Though it does not need to prove factual truth, it targets at a much broader and ubiquitous truth, which is also one of the essential pursuits of philosophy. Philosophy aims at revealing the nature of things, the very nature, however, is closely connected with human perspective, human understanding and human existence. The "self-contained" philosophy without any literary metaphors could both be imaginary and harmful. When philosophy is on its way of purity, it is also on the way of petrification. Heidegger once clarified in one of his two-hour courses that "Phenomenology is the investigation of life in itself. Despite the appearance of a philosophy of life, it is really the opposite of a worldview. A worldview is an objectification and immobilizing of life at a certain point in the life of a culture. In contrast, phenomenology is never closed off, it is always provisional in its absolute immersion in life as such. In it no theories are in dispute, but only genuine insights versus the ungenuine. The genuine ones can be obtained only by an honest and unreserved immersion in life itself in its genuineness, and this is ultimately possible only through the genuineness of a personal life." [12] Though philosophy and literature have their own special ways to achieve their goal, there is natural and historical bond within them. The long-lasting literary memory in philosophy should not and cannot be overlooked.

\section{CONCLUSION}

The strange institution which is called literature aims not at the factual life and abstract concepts. Instead, it targets at the same thing that philosophy naturally and genuinely purses-authenticity of human life. Literature provides exactly the genuineness of individual life in its unique authenticity. As Jacques Derrida said in his Acts of Literature, "What we call literature implies that license is given to the writer to say everything he wants to or everything he can, while remaining shielded, safe from all censorship, be it religious or political." [13], the self-given crown of free will in literature justifies its own existence. Similarly, in order to answer the essential and ultimate questions, philosophy is closely bonded with literature in this sense. Acknowledging and re-connecting the kinship to literature is a way to re-examine its motivation and goal. For the ongoing development of philosophy, it should firstly break the ingrained patricidal anxiety. Instead of expelling poets, expelling anxiety should be the aim for the development of philosophy. Faktisches Leben is not and should not be the end of philosophy. It should cross the mist of pure theoretical and metaphysical concepts and enter into a new domain which is based on every possible expression of human experience in a flowing and ever-changing human history.

\section{ACKNOWLEDGMENT}

The author would like to express her sincere gratitude to associate professor Song Shi and Yewei Wang in School of Foreign Studies, Minzu University of China for their generous support and guidance.

\section{REFERENCES}

[1] Jacques Derrida, Acts of Literature, Derek Attridge, Routledge, 1992, p.37.

[2] Plato, The Republic, trans. Benjamin Jowett, Devoted Publishing, Ontarios Inc. 2017, p130.

[3] Aristotle, Poetics, The Norton Anthology of Theory and Criticism, W.W. Norton\& Company, Inc.2001, p98.

[4] Harold Bloom, The Anxiety of Influence, Oxford University Press, 1997, p10. 
[5] Hong Yu, "Derrida: The Literary Criticism of Deconstructing Philosophy," Foreign Literature Studies, vol.1, p11, 2004.

[6] Jonathan Culler, On Deconstruction: Theory and Criticism after Structuralism, Routledge, 1983, p147.

[7] Jacques Derrida, Margins of Philosophy, trans. Alan Bass, The Harvester Press, 1982, p294.

[8] Heidegger, Zur Bestimmung der Philosophie, Gesamtausgabe Bd.56/57. Frankfurt am Main: Vittorio Klostermann, 1987. p163.

[9] Friedrich Hölderlin, Hymns and Fragment, trans. Richard Sieburth, Princeton University Press, 1984, p249. https://doi.org/10.1515/9781400883998

[10] Hans-Georg Gadamer, Truth and Method, trans. Joel Weinsheimer and Donald G. Marshall, 2006, p20.

[11] Theodore Kisiel, The Genesis of Heidegger's Being and Time, University of California Press, 1995, p17.

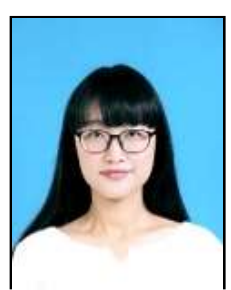

Ying Zhou, Chinese, born in May, 1995. Master student, major in comparative literature and world literature in Minzu University of China, Beijing, China.

Her previous publish article: The Awareness of National Culture and the On-going Practice in College English Class-A case Study on the Course Western Writers and Chinese Culture, Beijing, China: Minzu University of China, 2018. Her research interests inciuge interaisciplinary literary studies, contemporary American literature and literature theory. 